REVUE DE L'INSTITUT

FRANÇAIS D'HISTOIRE

EN ALLEMAGNE
Revue de I'IFHA

Revue de l'Institut français d'histoire en Allemagne

$5 \mid 2013$

IFHA 5

\title{
Le Mediävistenverband
}

\section{Philippe Cordez}

\section{OpenEdition}

\section{Journals}

Édition électronique

URL : http://journals.openedition.org/ifha/7389

DOI : 10.4000/ifha.7389

ISSN : 2198-8943

\section{Éditeur}

IFRA - Institut franco-allemand (sciences historiques et sociales)

Édition imprimée

Date de publication : 1 décembre 2013

ISSN : 2190-0078

Référence électronique

Philippe Cordez, "Le Mediävistenverband », Revue de l'IFHA [En ligne], 5 | 2013, mis en ligne le 17 février 2014, consulté le 03 mai 2019. URL : http://journals.openedition.org/ifha/7389 ; DOI : 10.4000/ ifha.7389

Ce document a été généré automatiquement le 3 mai 2019.

(CIFHA 


\title{
Le Mediävistenverband
}

\author{
Philippe Cordez
}

1 Le Mediävistenverband ou « Association des médiévistes » (www.mediaevistenverband.de) a été fondé en 1983 dans le but de favoriser les échanges entre médiévistes de disciplines diverses. ${ }^{1}$ Si son siège administratif est à Francfort-sur-le-Main, et si la plupart de ses membres sont germanophones, le Mediävistenverband accueille volontiers quiconque souhaiterait participer à ses diverses activités : il offre ainsi de fait une entrée privilégiée à celles et ceux qui s'intéressent au Moyen Âge des pays de langue allemande, ou souhaiteraient mieux connaître les médiévistes de ces régions. L'association compte à ce jour un peu plus de 1100 membres, dont environ $12 \%$ d'étudiants, lesquels sont encouragés à adhérer par une cotisation annuelle au montant réduit ( $20 €$ au lieu de $50 €$ ). La répartition statistique des disciplines ainsi représentées montre un fort engagement des historien(ne)s $(38 \%)$ et des germanistes $(29 \%)$, tandis que le dernier tiers des adhésions est réparti entre d'une part les représentants d'une petite dizaine d'autres disciplines - l'histoire de l'art (6\%), la philologie latine et anglaise (4\% chacune), la romanistique $(3 \%)$, la théologie, la musicologie $(2 \%)$, la philosophie, les études scandinaves et byzantines ( $1 \%)$ - et d'autre part ceux que l'on a classés dans la rubrique «autres» $(8 \%)$ et enfin quelques maisons d'édition (1\%). Sans être une organisation strictement professionnelle comme l'est la Société des Historiens Médiévistes de l'Enseignement Supérieur en France (http://www.shmesp.fr/), le Mediävistenverband dispose ainsi de la légitimité nécessaire pour lui permettre à l'occasion de représenter les intérêts communs des médiévistes dans la politique universitaire - on notera à ce propos l'utile instrument qu'est l'annuaire des chaires médiévistes en Allemagne, Autriche et Suisse, classées par disciplines, publié sur le site. Outre le comité de direction, l'association est animée par un comité scientifique doté de vingt membres au maximum qui sont chargés soit de représenter leurs disciplines respectives (une quinzaine en tout), soit d'assumer des tâches particulières (les relations publiques, les contacts avec la relève scientifique, et les rapports entre les études médiévales et l'enseignement scolaire).

2 La première publication du Mediävistenverband a été un bulletin d'information, la Mitteilungsblatt des Mediävistenverbandes e.V., dont onze numéros sont parus entre 1984 et 
1994 et qui annonçait congrès, publications et autres projets. Depuis 1996, la Mitteilungsblatt a été remplacée par une véritable revue scientifique, intitulée Das Mittelalter. Perspektiven mediävistischer Forschung, qui paraît deux fois par an sous la forme de cahiers généralement forts d'un peu plus de 150 pages, parfois avec quelques images en noir et blanc. Les dernières trente ou quarante pages prolongent la Mitteilungsblatt, dans une section appelée Forum Mittelalter, à ceci près que les simples annonces, circulant désormais plus efficacement par d'autres voies, cèdent maintenant la place d'une part aux présentations plus substantielles (ainsi récemment sur la médiévistique en Suisse, ou sur le projet européen de mise en réseau de bases de données «Medieval Europe Medieval Cultures and Technological Resources »), et d'autre part aux comptes-rendus de livres, à raison d'une trentaine par livraison. Le corps de la revue est constitué quant à lui par des dossiers thématiques, qui ont à chaque fois un éditeur propre (parfois deux), et qui regroupent en général sept à dix articles autour d'un thème propre à fédérer des recherches ancrées dans plusieurs disciplines, avec une introduction et éventuellement une bibliographie. On trouvera sur le site de l'association les sommaires de cette revue, dont le format et les intentions rappelleront Médiévales aux lecteurs francophones ( http://medievales.revues.org/).

3 La langue est ici très majoritairement l'allemand (les quelques textes parus en français ou en anglais doivent représenter environ $2 \%$ du total), mais tous les médiévistes sont invités à proposer des cahiers thématiques, les décisions étant prises sur la base d'une évaluation à plusieurs niveaux par le comité scientifique de l'association. La diffusion de la revue, assez importante, est très liée à l'association puisque tous ses membres la reçoivent, tandis que le prix public de l'abonnement s'élève à plus du double de la cotisation: De Gruyter, qui vient de racheter Akademie Verlag, propose la version imprimée à $118 €$ par an et une version électronique à $49 €$ pour les seuls numéros parus depuis 2008. À en juger d'après SUDOC, seules quatre bibliothèques françaises, malheureusement, ont en ce moment des abonnements actifs, la seule collection complète se trouvant à Poitiers - celle de l'Institut Historique Allemand mise à part. Il serait certainement souhaitable que les anciens numéros puissent être mis à disposition en libre accès. Une série de suppléments (Beihefte) à la revue est prévue, où doivent être publiés des volumes collectifs ou des monographies, dont des traductions, en ajoutant l'exigence de l'internationalité à celle de l'interdisciplinarité.

Depuis 1984, le Mediävistenverband organise tous les deux ans un colloque qui constitue un important moment de rencontre des médiévistes germanophones, et dont chaque édition a lieu dans une ville différente (en Allemagne sauf exception). Ces évé ${ }^{2}$ ements sont suivis de publications substantielles, avec des livres regroupant vingt-cinq à trente articles en 400 à 500 pages, sous la direction de l'organisateur/trice local(e) du colloque le treizième volume et dernier paru, sur "La couleur au Moyen Âge", se faisant spécialement monumental avec soixante-dix articles sur 1130 pages. Le dernier de ces grands colloques s'est tenu à Heidelberg en mars 2013 sur le thème de "L'héritage d'Abraham. Concurrence, conflit, coexistence au Moyen Âge »; le prochain est prévu à Berne en 2015 et portera sur «L'usage et la symbolique de l'eau dans la culture médiévale »: les propositions de sections, qui doivent réunir trois ou quatre contributions relevant de deux ou trois disciplines différentes, peuvent être soumises jusqu'au 28 février 2014. Une autre manifestation régulière du Mediävistenverband est l'académie d'été interdisciplinaire organisée chaque année depuis 2000 en collaboration avec l'Université Heinrich-Heine de Düsseldorf : le thème en est à chaque fois différent 
(ainsi la cathédrale en 2011, la chasse en 2012, la communication par lettre et la documentation des lettres en 2013) et réunit pour cinq jours vingt-cinq étudiants (à partir du cinquième semestre) autour d'un petit groupe de professeur(e)s venus de plusieurs universités.

5 La dernière-née des initiatives du Mediävistenverband est enfin l'attribution annuelle d'un prix (doté de $2000 €$ ) destiné à récompenser une thèse portant sur le Moyen Âge et adoptant une approche interdisciplinaire. Le jury est constitué du comité scientifique de l'association. J'ai eu l'honneur que la première édition de ce Nachwuchspreis soit décernée pour ma propre thèse ${ }^{2}$, lors du dernier colloque de l'association à Heidelberg en mars 2013 : je peux donc finalement avec un grand plaisir présenter ces quelques lignes en guise de remerciement, tout en invitant chaleureusement les médiévistes francophones à s'intéresser de plus près aux activités du Mediävistenverband, ou à y participer.

\section{NOTES}

1. Je remercie Ingrid Baumgärtner (trésorière) pour m'avoir communiqué des informations chiffrées, ainsi que Klaus Oschema (responsable des relations publiques) pour sa relecture.

2. Philippe CORDEZ, Trésor, mémoire, merveilles. Les objets des églises au Moyen Âge, EHESS Paris et Humboldt-Universität zu Berlin, 2010, résumé in : Revue de l'Institut Français d'Histoire en Allemagne, 3, 2011, p. 142-145. La publication est en préparation, ainsi qu'une traduction allemande.

\section{AUTEUR}

\section{PHILIPPE CORDEZ}

Université Ludwig-Maximilian de Munich. Philippe Cordez dirige depuis octobre 2013 le Groupe de Recherches Junior « Objets prémodernes. Une archéologie de l'expérience » (Elitenetzwerk Bayern) à la Ludwig-Maximilians-Universität de Munich. 